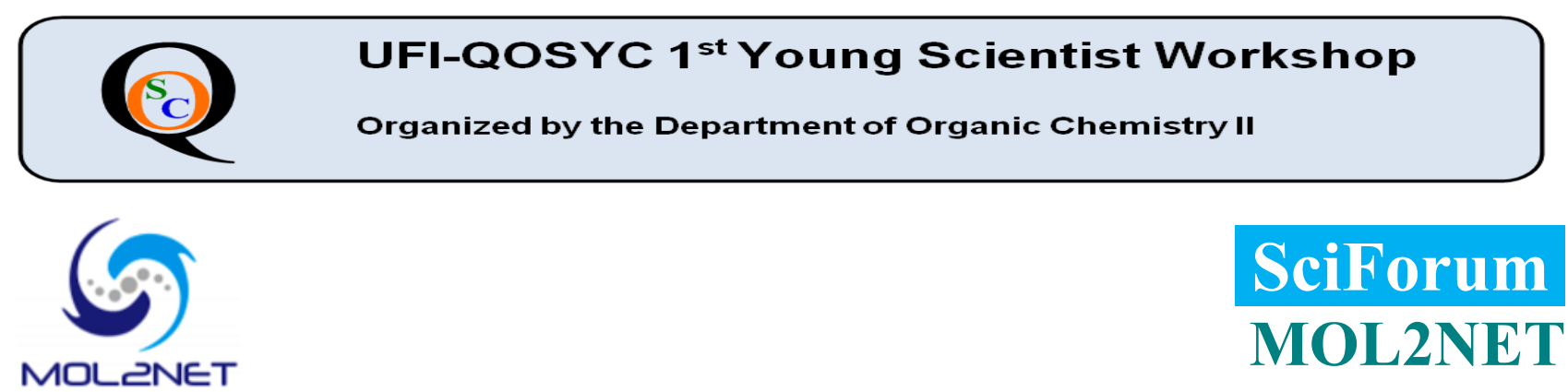

\title{
Intramolecular Palladium-catalyzed C-H activation reactions: Synthesis of substituted quinolones
} Verónica Ortiz de Elguea, Nuria Sotomayor, and Esther Lete

Departamento de Química Orgánica II, Facultad de Ciencia y Tecnología, UPV/EHU, P.O. Box 644, 48080 Bilbao, Spain

\section{veronica.ortizdeelguea@ehu.es}

In the last years, the Palladium-catalyzed direct alkenylation of $\mathrm{Csp}^{2}-\mathrm{H}$ bonds, an oxidative variant of the Heck reaction known as Fujiwara-Moritani reaction, has emerged as an efficient, atom-economical, and environmentally friendly synthetic tool for the preparation of highly functionalized aromatic molecules. In connection with our work in catalytic $\mathrm{C}-\mathrm{H}$ activation chemistry, ${ }^{1}$ we decided to apply this procedure to the synthesis of polysubstituted quinolone scaffolds, an important structural motif embedded in a wide variety of bioactive natural products and pharmaceuticals. An efficient approach to the synthesis of biologically active 3-alkenyl-4-substituted quinolin-2(1H)-ones that involves two sequential $\mathrm{C}-\mathrm{H}$ alkenylation reactions has been developed. First, a $\mathrm{Pd}(\mathrm{II})$ catalyzed selective 6-endo intramolecular C-H alkenylation of $\mathrm{N}$ phenylacrylamides has allowed the construction of the quinolone core, which could be further functionalized in C-3 through a second intermolecular C-H alkenylation reaction. This method is a significant advance over the existing procedures that require preactivatated reaction partners. Furthermore, these reactions can also be carried out in aqueous media at room temperature, using a $2 \%$ aqueous solution of PTS, or even in water, in good yields. Details of these transformations will be given.

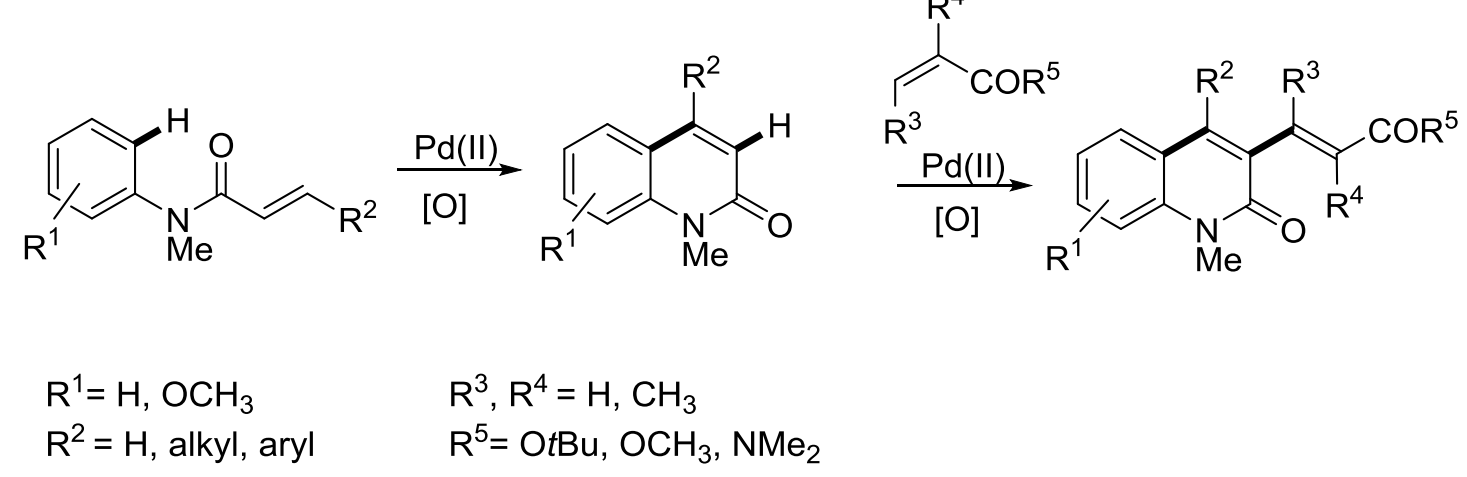

Acknowledgements: Financial support by the Spanish MICINN (CTQ2009-07733), the Basque Government (IT623-13) and UPV/EHU (UFI QOSYC 11/22) is gratefully acknowledged. We also thank Gobierno Vasco for a grant (V.O-E)

1. (a) Lage, S.; Martínez Estíbalez, U. Sotomayor, N. Lete, E. Adv. Synth. Catal.. 2009, 351, 2460. (b) Coya, E.; Sotomayor, N. Lete, E. Adv. Synth. Catal. 2014, 356, 1853. 